\title{
THE EFFECT OF ENFORCEMENT UPON SERVICE OF ALCOHOL TO INTOXICATED PATRONS OF BARS AND RESTAURANTS
}

\author{
A. James McKnight ${ }^{1}$ and Fredrick M. StrefF ${ }^{2}$ \\ 'National Public Services Research Institute, 8201 Corporate Drive, Landover, MD 20785, U.S.A.; \\ ${ }^{2}$ University of Michigan, 2901 Baxter Drive, Ann Arbor, MI 48109-2150, U.S.A.
}

(Received 19 September 1992; in revised form 25 March 1993)

\begin{abstract}
Laws prohibiting the service of alcohol to already intoxicated patrons of bars and restaurants are seldom enforced. Following introduction of an enforcement effort in Washtenaw County, Michigan, observed refusals of service to "pseudopatrons" simulating intoxication rose from $17.5 \%$ to $54.3 \%$, declining eventually to $41.0 \%$. At the same time, the percentage of those arrested drunk drivers coming from bars and restaurants declined from $31.7 \%$ to $23.3 \%$. In a comparison county, refusals of service rose to a significantly smaller extent, from $11.5 \%$ to $32.7 \%$, while the percentage of DWIs coming from bars and restaurants showed no significant changes. Service refusals were related to volume of business and numbers of intoxicated patrons in an establishment at the time of observation, while numbers of arrested DWIs was related to the nature of the establishment's clientele, policies, and practices. While enforcement of alcohol service laws offers a potentially cost beneficial means of reducing highway crashes, replication across additional jurisdictions is needed.
\end{abstract}

\section{BACKGROUND}

In $1989,37 \%$ of drivers killed in automobile crashes were intoxicated, that is, blood alcohol content $(\mathrm{BAC})>.10 \%$ (FARS 1991). In recent years, increased emphasis has been placed upon restricting alcohol at the point of sale as a means of reducing alcohol-related automobile crashes and other unacceptable consequences of alcohol abuse. Roadside surveys disclosed that the leading source of intoxicated drivers, accounting for approximately onethird of them, has been licensed on-sale establishments, such as bars and restaurants (Ontario MinisIry of Transportation and Communication 1980; Palmer 1986; Fell 1988; Foss et al. 1990; Voas and Holder 1993). Breath tests given to patrons leaving bars end restaurants have shown approximately a third of them to have blood alcohol levels in excess of the legal limit (Werch et al. 1988; Stockwell et al. 1992).

Except in a few jurisdictions, the service of alcohol to intoxicated patrons is prohibited by state or local law as well as liquor control regulation. In addition, so-called dram-shop laws in 29 states (25 by statute, 4 by common law) allow third parties injured in accidents resulting from the service of alcohol to intoxicated patrons, to recover damages from licensed establishments (NHTSA 1990). Given the numbers of DWIs who come from licensed est $b$ lishments, it is evident that these legal measures have not prevented intoxicated patrons from being served or from leaving licensed establishments in an intoxicated condition.

\section{Alcohol server intervention}

The past decade has seen a major effort to $\mathrm{n} n$ courage voluntary compliance on the part of servers of alcohol with laws prohibiting the sale of alcoholic beverages to intoxicated patrons. Generally referrıd to as "server intervention," these efforts are imp/2mented by bartenders, waiters, waitresses, maniıers, and owners, and have been most comprehe 1sively described by Mosher et al. (1990). As a mea is of reducing alcohol-involved crashes, interventi n efforts have an advantage over driver-oriented appeals of not relying upon the judgment of someo who is already impaired by alcohol. For the past file years, ever-increasing numbers of server educatic $n$ programs have been developed and taught. Sev n states and many municipalities have enacted law's that either mandate server education directly or create conditions that make it virtually a necessity thit establishments employ trained servers.

Evaluations of server training programs have shown significant shift toward more responsible se :- 
vice practices on the part of both servers and managers of licensed establishments (Russ and Geller 1986; Saltz 1987; Glicksman and Single 1988; McKnight 1988; Howard-Pitney et al. 1991; Molof and Kimball, 1992). Favorable outcomes were, however, largely limited to those efforts aimed at preventing patrons from becoming intoxicated. Only one of these studies, McKnight (1988), examined the effects of server education programs upon service to already intoxicated patrons. The results were extremely discouraging. Such intervention occurred only $5 \%$ of the time before training and $7 \%$ of the time after participation in training.

The apparent disinclination of even trained servers to intervene in the consumption of alcohol by already intoxicated patrons suggests consideration of the incentives involved. Incentives to intervene include whatever intrinsic reward derives from discharging one's obligation to uphold the law and protect the public, as well as the extrinsic rewards of reducing one's exposure to financial loss in the form of fines for the server and owner and possible suspension of license. The incentives to continue service include the server's prospect of confrontation with the patron, with attendant loss of gratuity, and the owner's prospect of losing continued business.

\section{Enforcement of alcohol service laws}

It is obvious from the low incidence of intervention with intoxicated patrons that incentives to continue service currently outweigh the incentives to intervene. One possible contributor to this imbalance is the very low threat of financial loss from fines and suspension due to lack of enforcement. An analysis of citations issued by enforcement agencies in the jurisdiction where the study about to be described took place revealed only two citations for service of alcohol to intoxicated patrons over a twoyear period. Sanctions that are not imposed cannot discourage responsible alcohol service. It appears that, with failure to enforce the law, the balance of incentives is presently tilted against intervention with intoxicated patrons.

The potential effects of enforcement upon the responsibility of alcohol service can be seen in an area in which enforcement efforts are fairly common-service of alcohol to the underaged. Preusser and Williams (1991) found that attempts by youth to purchase beer from retail stores in a city characterized by frequent "stings" (underage purchase attempts initiated by the police) were successful $44 \%$ of the time, as opposed to an $80 \%-97 \%$ success rate where such enforcement was absent. In the jurisdiction where the study here described took place, sales of alcohol to minors engaged in a sting operation some years earlier dropped from $67 \%$ to $43 \%$ following an intensified enforcement effort. The currently high rate of alcohol service to the intoxicated throughout the United States, coupled with the general failure to enforce laws prohibiting such service, is cause to believe that the introduction of an enforcement effort might yield reductions in sales similar to those experienced in connection with underage drinking.

\section{Study objective}

The objective of the study described in this report was to assess the effects of enforcing laws prohibiting the service of alcohol to intoxicated patrons of bars and restaurants. Specifically, it addressed the following questions:

1. What is the effect of enforcement upon the service of alcohol to intoxicated patrons?

2. What impact does any change in service to the intoxicated have upon the relative numbers of DWIs coming from bars and restaurants?

3. How do the costs of enforcement relate to the estimated cost savings yielded by projected reductions in alcohol-related accidents?

\section{METHODOLOGY}

Plainclothes officers from enforcement agencies in Washtenaw County, Michigan, entered bars and restaurants periodically throughout a one-year period to watch for and cite servers found dispensing alcohol to intoxicated patrons. The effects of enforcement were assessed through pre-post comparisons of (i) service to "pseudopatrons" simulating visible signs of intoxication and (ii) relative numbers of arrested DWIs coming from bars and restaurants. This study took place in Washtenaw County, Michigan, with the participation of the Ann Arbor Police Department, Washtenaw County Sheriff's Department, and the University of Michigan Transportation Research Institute.

\section{Enforcement of alcohol service laws}

The independent variable under study was the level of effort applied to enforcement of state laws and liquor control regulations prohibiting the service of alcohol to intoxicated patrons of bars and restaurants in Michigan. Two levels of enforcement were involved, the almost zero level prevailing prior to initiation of the enforcement intervention and the intervention itself, which required an average of 10 
personnel hours of enforcement per week over a one-year period by each of the two participating enforcement agencies. This added up to onc-half a personnel-year across the county for the one-year program, the amount of time that heads of the agencies involved indicated they would be willing to devote undercover enforcement should it prove effective in reducing service to intoxicated patrons.

Since the deterrent effect of any enforcement effort requires that the objects of enforcement be aware of it, three steps were taken to give visibility to the effort: a presentation to which the county's 205 licensees were invited (and which 105 attended) during which the law enforcement effort was annouriced, explained, and discussed; after-visit reporti: to those licensees, who were visited by enforcement officers but not cited, notifying them that they had been the objects of enforcement; and media coverage, including feature stories about the enforcement effort and its effects upon individual establishments. The efforts to maintain visibility were limited to those that would ordinarily be a part of an eriforcement effort and were not intended to form a special information program or "campaign."

In addition to informing licensees of the enforcement effort, a number of steps were taken to facilitate enforcement itself. One obstacle to enforcement of prohibitions upon serving alcohol to the iatoxicated is the subjectivity of the signs by which servers are to judge whether a patron is intoxicated. From a study of observable impairment signs reported by McKnight and Marques (1989), seven signs associated with BACs in excess of $.08 \%$ were selected as the bases of enforcement, and presented to servers through a brochure and a ten-minute video. In addition to clarifying the nature of illegal alcohol service, the specification of impairment signs aided servers in justifying, to intoxicated patrons, the need to terminate alcohol service. To aid further in getting the support of patrons, tent cards explaining alcohol service laws to customers in seeking thieir support were supplied to licensees upon request.

One-half of the enforcement visits were concentrated upon the ten establishments responsible for the greatest number of drinking drivers, as obtained from eports of arrested DWIs, while the other half was randomly distributed over the remaining establishments within Washtenaw County. Following a practice frequently used by enforcement agencies when intensive enforcement is first introduced, officers were required only to issue "warnings" during the first three months of the year-long enforcement effort. However, this fact was not announced to the licensees, and the only ones who knew about the warning where those violators who would have stherwise been cited.

\section{Assessing effect upon alcohol service}

Since the enforcement effort was directe $I^{l}$ at servers of alcohol, its most immediate effect sh uld have been a change in the incidence of alcohol iervice to intoxicated patrons. An earlier study ad disclosed the need for an average of 1.5 hour: of observation to witness a request for alcohol ser 'ice by an intoxicated patron (McKnight 1991). A n ore uniform and efficient way of assessing server bel avior was to send "pseudopatron" observers intc establishments to exhibit signs of alcohol impairn ent and to request a drink. Procedures for data collec $\mid$ ion and for training and monitoring pseudopatron observers followed those employed in the earlier st $1 \mathrm{dy}$, which involved over 1,500 visits to bars and res aurants for observations of alcohol service. Candiciate observers participated in a three-hour training ession during which they practiced feigning intoxication while ordering drinks in simulated bar and I estaurant settings. All performances were videotal ed and the three most convincing candidates were ielected. All were males (no females applied) aıt, falling within the 21- to 25-year age range, were a ole to enter almost any type of drinking establishm without appearing to be out of place. Each obser :er employed a specific approved and well-reheared routine. Visits to specified drinking establishme its were assigned by hour and day so that performar ce could be monitored on a spot-checked basis $b$ : a staffmember unknown to them (but able to ident fy them from the videos).

The pseudopatron observers visited each of 40 randomly selected bars and restaurants in the exp rimental county on four occasions: preintervent on phase - the month prior to initiation of the enfor:ement effort in July 1990; warning phase-after he first three months of the enforcement effort; $f_{t}-s t$ citation phase - after the program had been in eff ct for six months (including three months of citation;); and second citation phase-after the program $t$ id been in effect for one year. The same pseudopation observers also visited each of 20 establishments in a comparison community, Ingham County (wh th includes the city of Lansing) at the same four poir ts in time as the visits in the experimental site. The two sites are similar in character and populatic $n$. but sufficiently distant from one another $(80$ milc s) to isolate the comparison community from the $f$ fects of the intervention.

The observed responses of servers to feigned intoxication were categorized as follows: no int $r$ vention-serving alcohol without comment; partial 
intervention-discouraging further consumption, but still serving alcohol; refusal-not serving alcohol. Observers, in addition to recording server response, noted numbers of other patrons and the number of them that appeared to be intoxicated and whether their orders were taken by a bartender or waitperson.

\section{Assessing effect upon drunk driving}

One of the two enforcement agencies, the Washtenaw County Sheriff's Department, routinely collected information as to the source of the last drink consumed by DWIs prior to their arrest. The availability of such data allowed the portion of arrested DWIs coming from bars and restaurants within the county to be tallied for the year prior to initiation of the enforcement program. Collection of the same data over the following year provided information on drink sources over comparable periods of time prior to and following the intervention. While the data were necessarily limited to arrests outside the city of Ann Arbor, the bars and restaurants from which those arrested had most recently come represented the entire county.

The use of reports by DWIs as to the source of their last drink must be treated with some caution. It is always possible that those arrested for drinking and driving might lie to protect their source. However, such reports were used by the California Department of Alcoholic Beverage Control to enroll establishments in a server education program (Mosher and Wallack 1979), and there is no indication that substantial numbers of establishments were incorrectly identified. It is also possible that officers on DWI patrol shifted their locations in a way that reduced relative numbers of arrested drivers coming from bars and restaurants. Certainly no change in official enforcement policy occurred. Nor is it likely that officers on DWI patrol were even aware of the alcohol service intervention, since there is rarely much interaction between traffic services and liquor control in a large law enforcement agency. Nevertheless, the potential for unreliable reporting or changing enforcement practices must be recognized.

\section{Assessing characteristics of establishments}

Stockwell et al. (1992) found the BACs of patrons leaving licensed premises to be related to characteristics of clientele such as occupation, alcohol preferences, and previous involvement in drunk driving accidents and violations. To permit assessment of such relationships within the present study, visits were made to 37 of the 40 establishments in the experimental sample. Information sought included not only the characteristics of clientele but the policies and practices of the establishments themselves. Of the three establishments that were not reached by the survey, one refused to participate, while arrangements for an interview could not be completed with the other two during the project. The interviews took place following the postintervention observations to avoid any chance that the interaction might influence study outcomes. The interviews were approximately an hour long and dealt with 53 items of beverage service: use of nonalcoholic beverages, food service, age identification, personnel management, dealing with intoxicated patrons, and response to alcohol enforcement efforts.

\section{RESULTS}

Over the one-year period following initiation of the enforcement effort, officers of the two agencies involved paid a total of 457 visits to licensed establishments throughout Washtenaw County. These visits produced 13 citations and 11 warnings for service to intoxicaled patrons. Eight of the warnings were issued during the warning phase; the remainder were issued during the citation phase in instances where officers observed violations but did not believe they could make a citation stick.

\section{Refusals of service}

The responses of servers to pseudopatrons is depicted graphically in Fig. 1. The percentage of observations resulting in refusals of service grows sharply from $17.5 \%$ prior to initiation of the enforcement effort to $54.3 \%$ after the first three months of enforcement. Over the next three months, it dropped to $47.4 \%$, and after one year to $41.0 \%$. All three postintervention refusal rates are significantly greater than the baseline rate $\left(\chi_{1}^{2} \geq 12.9 ; p<.001\right)$.

Results of observations recorded in the comparison (Ingham) county appear in Fig. 2. They follow the same pattern as that observed in the experimental county except that the refusal rates are consistently lower during each of the postintervention observation periods. While each of the first two postintervention refusal rates significantly exceeds that of the baseline rate, $\left(\chi_{1}^{2} \geq 5.5 ; p<.05\right)$, the third does not $\left(\chi_{1}^{2}=3.4 ; p=.07\right)$. It is noteworthy that the increase in service refusals within both the experimental and comparison sites is accompanied by a decline in "partial intervention," that is, steps to discourage drinking. It appears that much of enforcement's effect was not to increase the ability of servers to recognize patron intoxication, but rather to motivate refusal of service by those who would otherwise only have discouraged consumption. 


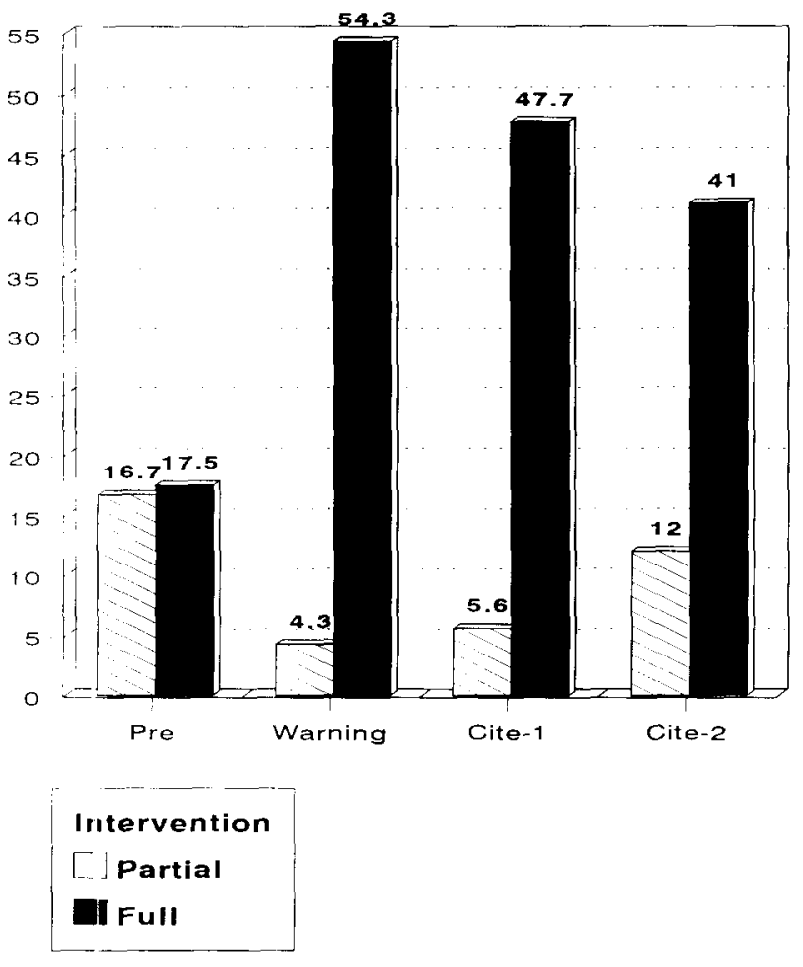

Fig. 1. Percentage of cases in which servers intervened with "pseudopatrons" simulating intoxication: experimental county.

Given the increase in refusal rates within the comparison site, a critical question is whether those increases match the increases in refusal rates observed within the experimental community. Comparisons between the sites discloses no significant difference during the preintervention phase $\left(\chi_{1}^{2}=\right.$ $0.6 ; p=.42$ ), indicating that any differences prior to introduction of enforcement effort in the experimental community can be easily attributed to chance. Of the differences in refusal rates between the two sites over the three postintervention phases, the first two differences are significant $\left(\chi_{1}^{2} \geq 4.3\right.$; $p<.05)$; while the third is not $\left(\chi_{1}^{2}=1.9 ; p=.17\right)$.

One of the three pseudopatron observers was forced to discontinue after the second data collection phase. On the basis of interobserver differences observed in the first two phases, results from the second two phases were statistically adjusted to preserve the comparability of refusal rates across the four phases.

\section{Sources of DWI}

While service refusals provide the most direct measure of enforcement's effect, a better measure of potential impact upon all vehicle alcohol-impaired driving would be the changes in the relative

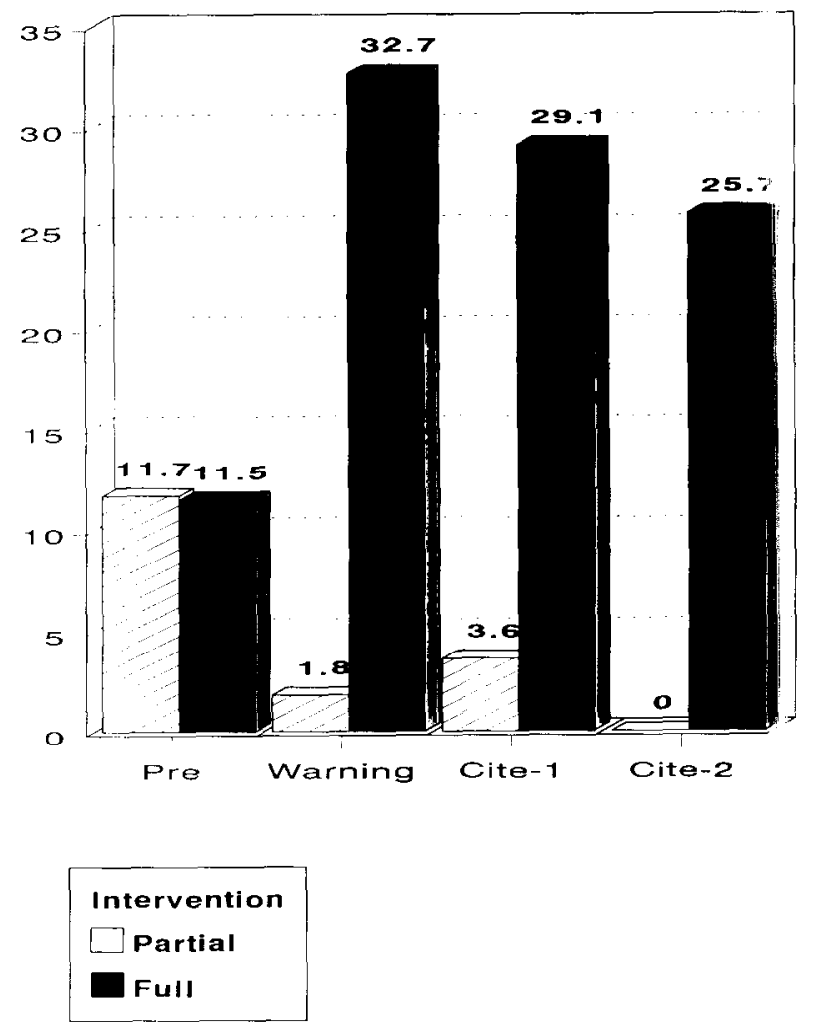

Fig. 2. Percentage of cases in which servers intervened wh "pseudopatrons" simulating intoxication: comparison count $"$.

numbers of arrested DWIs coming from bars ard restaurants.

Figure 3 displays the percentage of DWI arre: :ees who reported having consumed their last drin $k$ in a bar or restaurant within the experimental coun $y$ (Washtenaw), the comparison county (Ingham), at d two additional counties that maintain records if drink sources (Kalamazoo, Kent). The one-four h decrease in the experimental county, from $31.7 \%$ $23.3 \%$, is statistically significant $\left(\chi_{1}^{2}=7.5 ; p<.01\right.$. None of the other changes even approaches statis 1 cal significance.

\section{Characteristics of establishments}

The characteristics of bars and restaurants mat ing up the study sample were analyzed for the ir influence upon alcohol service and the effects of enforcement. Since the purpose in analyzing characteristics of establishments was to help account $\mathrm{f}_{\mathrm{C}} \mathrm{I}^{\circ}$ any observed differences in the effects of enforce. ment, analysis involved only those establishment:3 making up the experimental site. Neither sample size nor data collection procedures at the comparison sit was designed to detect the interaction of establish. ment characteristics with enforcement effects. How. 


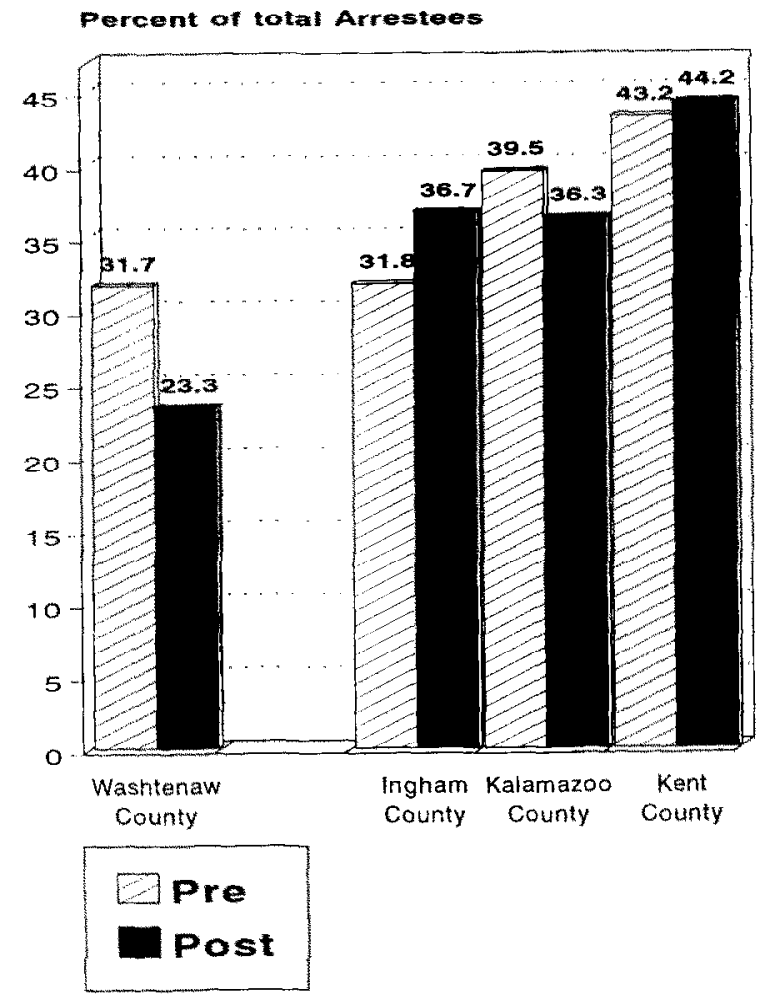

Fig. 3. Percentage of arrested DWIs coming from bars and restaurants by county.

ever, as it turned out, no apparent interactions were found between characteristics of establishments and the effects of enforcement upon either refusals of service or DWI arrests. Therefore, the study of establishment characteristics is confined to analysis of main effects upon service refusals and arrests.

Attempts to identify specific characteristics of bars and restaurants associated with refusals of service were largely unproductive. Only three of the 53 survey questions dealing with characteristics of establishments evidenced relationships with service refusals significant at the .05 level, just about what might be expected by chance alone. Those items showed the establishments having the greatest number of service refusals to be (i) more likely to require that cases of questionable age be referred to managers, (ii) less likely to have disciplined or teminated an employee for illegal alcohol service, and (iii) less likely to have been visited by law enforcement officers in connection with alcohol service. While these outcomes are consistent with expectation, they do not provide strong evidence that differences in likelihood of intervention are associated with characteristics of the establishments.

An explanation of the lack of significant relationships between establishment characteristics and service refusals may be found in the low intraclass

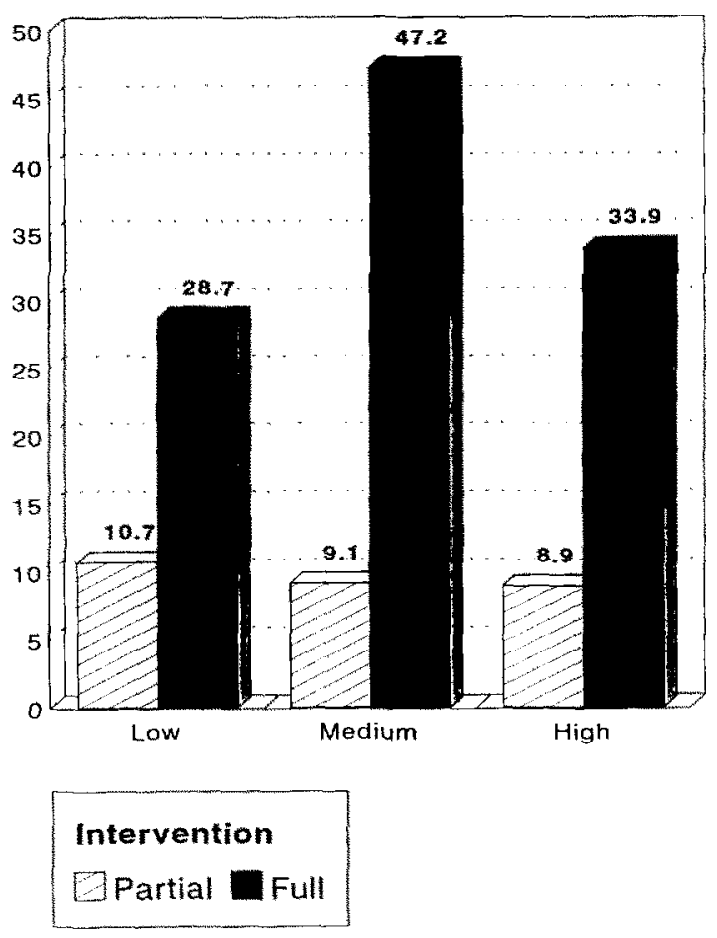

Fig. 4. Percentage of visits resulting in intervention by volume of business at the time of obscrvation (cxperimental site).

correlation of refusals from one data collection phase to the next. Mean intraclass correlation across experimental establishments was .13 , a nonsignifcant relationship $(p=.08)$. If the service refusals are not a stable characteristic of drinking establishments, there is little hope that they will correlate with other characteristics of those establishments.

Observations of the establishment's business volume at the time pseudopatrons requested service (Fig. 4) showed significant relationships with the level of server responses to pseudopatrons, servers being more likely to intervene when the volume of business was moderate (between quarter and half full) than when business volume was at either extreme. The relationship approached statistical significance when intervention was assessed in terms of percentage of times service was refused $\left(F_{2,272}=\right.$ $2.7 ; p=.07)$ and was highly significant when assessed in terms of intervention level $\left(F_{2.409}=15.7\right.$; $p<.001$ ). It is worth noting that the same curvilinear relationship between business volume and intervention level was observed in the eight-state evaluation of server training cited earlier (McKnight 1991). Intervention level was also found to vary with the presence or absence of already-intoxicated patrons at the time the pseudopatron observers were present. Across the four study phases, the chances of being intervened with were significantly greater 
when observers saw no truly intoxicated patrons than when they saw one or more intoxicated patrons $\left(F_{1,12:}=7.4 ; p-.01\right)$.

While not a characteristic of establishments themselves, the clientele who patronize establishments have been shown to influence and bear upon the ir cidence of overdrinking within an establishment Stockwell et al. 1992). However, in this study, refuscls of service were totally unrelated to whether the clientele was primarily white-collar vs bluecollar $\left(F_{1,037}=0.1 ; p=.76\right)$ or whether the establishment was classified as "upscale" (lounges and expensive restaurants), "midscale" (family restaurant), or "downscale" (tavern, college hang-out) $\left(F_{4,340}=1.6 ; p=.19\right)$.

Study of establishment characteristics also included examining the relationships of such characteristics to the numbers of arrested DWIs coming from a particular establishment. A correlation of .72 between pre- and postperiod DWI arrests evidenced some consistency over time, $(p=<.001)$. DWI arrests proved to be unrelated to mean intervention level of establishments $(r=-.17 ; p>.15)$. However, correlating responses to the survey with number of DWIs yielded 11 significant relationships, considerably more than would be expected by chance. Establishments that were sources of one or more drunk drivers during the year-and-a-half prior to and following initiation of the enforcement program were characterized by the following practices: selling special dr nks containing more than $2 \mathrm{oz}$. $(.52-.60 \mathrm{ml}$ or gm equivalents) of absolute ethanol ( $r=.30$; $p=.04)$, selling doubles and triples $(r=.50, p<$ $.001)$, collecting for drinks after every round $(r=$ $.59, p<.001)$, selling pitchers of beer $(r=.39$, $p<.01$ ), using tent cards to explain alcohol policies $(r=.29, p=.05)$, providing free coffee late at night $(r=.33, p=.03)$, not requiring that instances of questionable age identification be referred to the manager $(r=.41, p<.01)$, requesting patrons to attest in writing that their I.D.s were checked $(r=$ $.33, p=.03$ ), having received a report of visit from law enforcement agencies $(r=-.34, p=.03)$, requiring immediate termination of service to impaired patrons $(r=.62, p<.01)$, and offering alternative nonalcohol beverages $(r=.73, p=.03)$.

While these relationships are not entirely inconsistent with expectation, they are explainable. Such practices as selling special drinks, doubles, triples, and pitchers of beer, as well as not referring questionable I.D. to managers and having been visited by the law are all associated with irresponsible alcohol service. While collecting for drinks after every round is a practice intended to discourage overdrinking, it may be characteristic of places where drinking is most likely to occur. Similarly, requiring patrons to attest that their I.D.s are checked, while a respor sible practice, is likely to be characteristic of places populated by youthful drinkers and higher inciden ce overdrinking. Finally, while use of tent cards and provision of free coffee would appear to be steps in the direction of more responsible alcohol service, their association with a high incidence of DWI arre st overdrinking may reflect response to the conditions likely to produce overdrinking.

A simple division of establishments by chari:teristics of their clientele showed those serving a primarily blue-collar clientele to be associated wi h approximately $21 / 2$ times the average number of DWI arrests as those establishments serving a $\mathrm{pli}$ imarily white-collar crowd $\left(F_{1.370}=4.8 ; F_{4,340}=\right.$ $3.3 ; p=.03$ ). Taverns and college hangouts we e responsible for 15 times the number of DWIs is midscale and upscale establishments $(p=.02)$. The average number of intoxicated patrons encounter. $d$ in an establishment across all visits failed to corr:late significantly with the number of DWIs $(p:=$ $.23)$.

\section{Cost benefit relationships}

A major obstacle to enforcement of laws prohil iting service of alcohol to intoxicated patrons is the cost of observing for instances of infractions of th: law. The total costs of the law enforcement effot needed to bring about decrease in alcohol servic? violations and DWIs from bars that has been described was $\$ 48,400$. The costs of a nationwide effort have been estimated at roughly $\$ 45.4$ million pe: year. Based upon the reduction in arrested DWI; coming from bars, Levy and Miller (1992), in a seps rate report, project the net savings in accident-re lated costs resulting from an enforcement activit: carried on to the national level to be $\$ 4.0$ billion in costs to the DWIs themselves, and a total of $\$ 12$. i; billion in cost to everyone involved in alcohol-re lated accidents. Assessment is based upon th formula:

$$
B=a \times b \times x \times \sum n_{\mathrm{i}} \times C_{\mathrm{i}}
$$

where $B$ = benefits from reduced drinking and driv ing, $a=$ the proportional reduction in DWIs from taverns, $=.361, b=$ proportion of DWIs currently coming from bars and restaurants $=.35, x$ is a factor that controls for the percentage of alcohol-related incidents that would have occurred in the absence of alcohol consumption $=.853$, and $\sum n_{\mathrm{i}} C_{\mathrm{i}}=$ the number of DWI incidents in a given year times the average costs per incident $=\$ 118.3$ billion, (the 
Table 1. Total costs of DWI crashes by incident severity and cost category

\begin{tabular}{|c|c|c|c|c|c|}
\hline & Fatal injury & \multirow{2}{*}{$\begin{array}{c}\begin{array}{c}\text { Nonfatal } \\
\text { injury }\end{array} \\
\$ 4,203\end{array}$} & \multirow{2}{*}{ PDO vehicle } & \multicolumn{2}{|c|}{$\begin{array}{l}\text { Costs for } \\
\text { all cases }\end{array}$} \\
\hline Medical & 6,693 & & & $\$$ & $4,127 \mathrm{M}$ \\
\hline Emergency services & 930 & 194 & 24 & & $218 \mathrm{M}$ \\
\hline Productivity & 665,453 & 7,919 & 35 & & $19,391 \mathrm{M}$ \\
\hline Employer costs & 6,679 & 530 & 31 & & $23 \mathrm{M}$ \\
\hline Administrative & 48,337 & 1,259 & 127 & & $2,474 \mathrm{M}$ \\
\hline Legal & 70,925 & 1,703 & - & & $2,869 \mathrm{M}$ \\
\hline Travel delay & 387 & 187 & 107 & & $543 \mathrm{M}$ \\
\hline Property damage & 8,059 & 3,231 & 1,157 & & $7,082 \mathrm{M}$ \\
\hline MONETARY COSTS & $\$ 807,473$ & 19,244 & $\$ 1,481$ & & $37,490 \mathrm{M}$ \\
\hline Quality of life & $\$ 1,977,529$ & 48,367 & - & & $80,832 \mathrm{M}$ \\
\hline COMPREHENSIVE COSTS & $\$ 2,785,002$ & 67,611 & $\$ 1,481$ & & $118,322 \mathrm{M}$ \\
\hline
\end{tabular}

total comprehensive costs for all DWI crashes). A breakout of these costs appears in Table 1. Dividing the $\$ 12.8$ billion dollars by the estimated annual cost of $\$ 48,400$ amounts to a benefit of $\$ 260$ for each dollar invested in enforcement. Based upon an estimated $\$ 37.49$ billion in monetary costs alone reduces the net benefit to $\$ 90$ per dollar of enforcement.

In arriving at their projected savings, Levy and Miller assume (i) only those savings resulting from reduced traffic risks (not including assault, household injury, and other risks associated with alcohol consumption), (ii) the proportion of those refused drinks who continue to drink elsewhere is minimal (and incalculable), (iii) traffic safety benefits from refusals of service are confined to reductions of those matching BACs in excess of .10\%, (iv) Washtenaw County is roughly representative of the United States (supporting data are provided in their analysis), (v) enforcement involves the same level of effort as that employed in the Washtenaw County study, and (vi) the effectiveness of the program, the benefits derived from the study remain the same over extended period of time.

\section{DISCUSSION}

The results of the enforcement effort could be appropriately described as promising. The three-fold increase in refusals of alcohol service to the intoxicated immediately following implementation of the enforcement effort represents a large change in server behavior, particularly in comparison with the changes that have resulted from efforts to modify behavior solely through training. The one-fourth decline $(31.7 \%-23.3 \%)$, in the proportion of DWIs coming from bars is also encouraging.

The effects of enforcement upon refusals of service and numbers of DWIs proved unrelated to characteristics of the establishments or their clientele. Nor were service refusals themselves directly related to characteristics of establishments, although the incidence of service refusals was greatest when the volume of business at the time server responses were observed fell in the middle range (one-half to three-quarters of capacity). For the most part, refusals of alcohol service to patrons were spread across the various types of establishments more or less equally.

Several characteristics of establishments proved to be related to the numbers of arrested DWIs coming from various bars and restaurants. Downscale establishments, such as taverns and college hangouts, evidenced 15 times as many arrested DWIs as did cocktail lounges or restaurants, while establishments that catered to a primarily blue-collar clientele had about $21 / 2$ times as many DWIs as those serving a primarily white-collar crowd. Serving practices and policies were also related to numbers of DWIs, but not in a simple manner. With those practices involving the actual service of alcohol, establishments that were the primary sources of DWIs exhibited the least responsible practices, e.g. selling doubles and triples, or pitchers of beer. However, they were more likely to report policies intended to protect against overservice of alcohol, such as stringent age identification practices and measures to encourage immediate termination of service to impaired patrons. One explanation for these seemingly paradoxical results would be that establishments associated with the high incidence of DWI arrests, while giving maximum encouragement to the sale of alcohol are, by that very fact, the ones most likely to find it necessary to institute policies that control for the adverse consequences of excessive drinking. That they are the source of DWI arrests may be more than the result of the amount of alcohol they sell than their lack of alcohol control policies.

Three aspects of the outcome presented make it somewhat less than conclusive. Probably the most disconcerting result is the extent to which apparent changes in alcohol refusals over time within the ex- 
perimental county parallel those found in a comparison county. If these changes represent the effect of somc broad influences affecting both counties, then the extent of change should legitimately be subtracted from the apparent impact of the enforcement effort in the experimental community. On the other hand, it is possible that the pattern of drink refusals withir the comparison county reflects the effect of some local influence that just happens to coincide with introduction of the intervention in the experimental county. The failure to see a decline in the proportion of arrested DWIs coming from bars and restaurants in the comparison county suggests that whatever increased the refusal rate within the 20 establ shments in which observations took place did not reduce drinking and driving throughout the county. This finding, along with the absence of any known circumstance that might have had a regionwide $t$ :ffect upon alcohol service, suggests that the results obtained from the experimental county are primarily the result of the enforcement effort taking place there and that those changes found in the comparison county are attributable to changes specific to tha: locale. However, alternative explanations cannol be discounted.

A second limitation to the conclusiveness of the study described is the extent to which the refusals of service tended to wane over time following the initial rise. Such a decline in compliance with a law is often seen at following its enactment or a change in its e fforcement, witness the long-term decline in compliance with the national $55 \mathrm{mph}$ speed limit after it was enacted following the fuel crisis of 1974 . Also contributing to the decline, in this instance, could also be the large turnover among alcohol service personnel. Maintaining a high rate of compliance might require repetition of the workshop and the putlicity that attended it on an annual basis.

The third characteristic of the study that undermines its conclusiveness is the fact that the enforcement program took place in only one county. If the mere emergence of an enforcement effect in this study is not dependent upon the characteristics of the experimental county, the magnitude of that effect is very likely to be. We know, for example, that the baseline service refusal rate of $17.1 \%$ greatly exceeds that found across eight communities (including the experimental county) in the study cited earlier (McKnight 1991), where the overall refusal rate without enforcement was only $7 \%$, even after a server education program. The influences that encouraged a refusal rate this high in the absence of enforcement could have helped foster a response to enforcernent that is more salutatory than could be achieved elsewhere. The estimated benefits from an alcohol service enforcement program capable of a one-fourth reduction in DWIs from bars and restaurants ranges from $\$ 90$ (monetary savings) to $\$ 260$ (total savings) for each dollar invested in enfor ement. Obviously, the program would be cost-bes eficial, even with benefits much reduced and co ts much increased. However, the cost-benefit projictions are based upon observed reductions in the pr oportion of arrested DWIs coming from bars and ristaurants during the study, an outcome subject to considerable experimental error. The estimat es must therefore be viewed as representing potent al rather than actuality.

In summary, simple enforecment of existiıg laws and regulations prohibiting service of alcohol $o$ already intoxicated patrons of bars and restaurarıts represents what appears to be a potentially co tbeneficial way of reducing accidental injury a d death. However, a conclusive estimate of enforc $3-$ ment's effect upon alcohol service and alcohol-ir'?paired driving awaits replication in other jurisdi:tions.

Acknowledgements - The work here described was carried cut under a grant from the National Institute of Alcohol Abuse a $1 d$ Alcoholism (NIAAA). The authors wish to acknowledge the co ttribution to this study of Tom Gray of the Washtenaw Coun $y$ Sheriff's Office and John Atkinson of the Ann Arbor Police D:-partment, who supervised enforcement efforts in their respecti ie agencies. Jacqui Gannon supervised the on-site observatio 15 while Elizabeth A. Langston oversaw the data collection effor" Thanks are due to A. Scott Tippetts, who carried out all statistic II analyses and Marcia W. Zior who prepared all printed material. including the manuscript of this article. Finally, the authors wi 1 to express their appreciation to Mary L. Ganikos and Susan 1. Martin of the NIAAA for their encouragement and assistance

\section{REFERENCES}

FARS (Fatal Accident Reporting System). Transportatio।t fatalities 1989. Washington, DC: National Highwa! Traffic Safety Administration; 1991

Fell, J. C. The need for a multidisciplinary approach $t$. reduce drink driving and injury. Presentation to th 11 th National Trauma Symposium, Baltimore, Mary land; 1988.

Foss, R. D. ; Perrine, M. W.; Meyers, A. M. ; Musty, R E. Voas, R. B. A roadside survey in the computer age In: Perrine, M. W., editor. International Committee or Alcohol, Drugs and Traffic Safety-T-89. Chicago, IL National Safety Council; 1990.

Glicksman, L.; Single, E. A field evaluation of serve intervention programs: Accommodating reality. Pre sented at the Canadian Evaluation Society Meetings Montreal, Canada: Canadian Evaluation Society; 1988

Howard-Pitney, B.; Johnson, M. D.; Altman, D. G., Hop kins, R.; Hammond, N. Responsible alcohol service A study of server, manager, and environmental impact Am. J. Public Health 18(2):197-198; 1991.

Levy, D.; Miller, T. A cost-benefit analysis of increased 
enforcement to reduce serving intoxicated patrons. Baltimore, MD: University of Baltimore and the Urban Institute; 1992.

McKnight, A. J. Development and field test of a responsible alcohol service program. Washington, DC: National Highway Traffic Safety Administration; 1988.

McKnight, A. J. Factors influencing the effectiveness of server-intervention education. J. Stud. Alcohol 52(5):389-397, 1991.

McKnight, A. J.; Marques, P. R. Host and server determination of alcohol intoxication level. Washington, DC: National Highway Traffic Safety Administration: 1989.

Molof, M. J.; Kimball, C. Server training models to reduce driving under the influence: An economic study. Eugene, OR: Integrated Research Services, Inc; 1992.

Mosher, J. F.; Wallack, L. M. The DUI project: A description of an experimental program to address drinkingdriving problems. Sacramento, CA: California Department of Alcoholic Beverage Control; 1979.

Mosher, J. F.; Delewski, C.; Saltz, R. F.; Hennessey, M. Monterey/Santa Cruz responsible beverage project: Final report. San Rafael, CA: Marin Institute for the Prevention of Alcohol and Other Drug Problems; 1989.

NHTSA. Digest of state alcohol-highway safety related legislation. Ninth edition. Washington, DC: National Highway Traffic Safety Administration; 1990.

Ontario Ministry of Transportation and Communication. The 1979 Ontario roadside BAC survey: summary report; Interminesterial Committee on Drinking and Driving. Ontario, Canada: Author; 1980.
Palıner, J. W. Minnesota roadside survey: Alcohol positive drivers. Saint Cloud, MN: Saint Cloud University; 1986.

Preusser, D. F.; Williams, A. F. Sales of alcohol to underage purchasers in three New York counties and Washington, D.C. Arlington, VA: Insurance Institute for Highway Safety; 1991.

Russ, N. W.; Geller, E. S. Evaluation of a server intervention program for preventing drunk driving. Final Report No. DD-3. Blacksburg, VA: Virginia Polytechnic Institute and State University, Department of Psychology; 1986.

Saltz, R. F. The roles of bars and restaurants in preventing alcohol-impaired driving: An evaluation of server education. Evaluation in Health Professions 10(1):5-27; 1987.

Stockwell, T.; Rydion, P.; Giannatti, S.; Jankis, E.; Ovendon, C.; Syed, D. Levels of drunkenness of customers leaving licensed premises in Perth, Western Australia: A comparison of high and low "risks" premises. Br. J. Addict. 87:873-887; 1992.

Voas, R. B.; Holder, H. Community prevention trials to reduce alcohol-involved accidental injury and death. Paper presented at the 1993 annual meeting of the Transportation Research Board, Washington, DC, 1993.

Werch, C. E.; Bakema, D.; Ball, M.; Lee, D. Cataloguing blood alcohol level and alcohol consumption data in field settings: Feasibility and findings. J. Stud. Alcohol. 49(6):561-566; 1988. 